\title{
Impact of Testosterone Therapy on hypogonadal patients unresponsive to phosphodiesterase-5 inhibitors alone: A systematic review and a meta-analysis
}

\section{Xiaowei Yu}

The First Hospital of Jilin University

Yanhong Liu

The First Hospital of Jilin University

Xiaoyuan Zhang

The First Hospital of Jilin University

Qun Wang ( $\nabla$ wangqunjlu@jlu.edu.cn)

First Hospital of Jilin University https://orcid.org/0000-0002-2803-3571

\section{Research article}

Keywords: PDE5 inhibitors, testosterone therapy (TTh), erectile dysfunction (ED), hypogonadism, meta-analysis

Posted Date: October 11th, 2021

DOI: https://doi.org/10.21203/rs.3.rs-962013/v1

License: @ (i) This work is licensed under a Creative Commons Attribution 4.0 International License. Read Full License 


\section{Abstract \\ Background}

Phosphodiesterase- 5 inhibitors as the first-line treatment for erectile dysfunction, when patients with hypogonadism fail to respond to phosphodiesterase- 5 inhibitors, the beneficial of addition testosterone therapy is a major concern for clinicians. The objective of this study was to collect and summarize the evidence that evaluated the benefit of addition testosterone therapy in hypogonadism fail to respond to phosphodiesterase-5 inhibitors.

\section{Methods}

Electronic literature searches of Cochrane Library, PubMed, MEDLINE and EMBASE databases were conducted up to October 2020 and included randomized controlled trials. Specifically, we were looking for papers where Erectile Function Domain Score differences between pre and post-treatment were used as the primary outcome after treatment of testosterone therapy alone, phosphodiesterase-5 inhibitors therapy alone, or a dual treatment of both testosterone therapy and phosphodiesterase-5 inhibitors. Secondary outcomes included the number of phosphodiesterase- 5 inhibitors non-responders who subsequently reported a satisfactory treatment of dual treatment with testosterone therapy and phosphodiesterase-5 inhibitors.

\section{Results}

A total of 4 studies that met our criteria, consisting of 326 patients. The Erectile Function Domain Score was significantly higher after treatment of testosterone combine with phosphodiesterase-5 inhibitors(4.88[4.18-5.57]), phosphodiesterase- 5 inhibitors with placebo(3.15[1.82-4.47]), and testosterone monotherapy (2.04[0.38-3.71]) compared with baseline. Dual treatment with testosterone and phosphodiesterase-5 inhibitors significantly improved Erectile Function Domain Score when compared with testosterone monotherapy (3.16, $95 \% \mathrm{Cl}: 1.79-4.53)$, Of $41.7 \%$ patients in the dual treatment group reported an improvement, compared to only $33.0 \%$ in phosphodiesterase- 5 inhibitors treatment group.

\section{Conclusions}

Combination therapy of testosterone and phosphodiesterase- 5 inhibitors seems most effective in men with both erectile dysfunction and hypogonadism who initial unrespond to phosphodiesterase- 5 inhibitors.

\section{Introduction}

In $27.7 \%$ of men with erectile dysfunction (ED), total testosterone (T) levels were found to be less than $300 \mathrm{ng} / \mathrm{dL}$ [1]. Unfortunately, research on the relationship between low testosterone and ED remains inconclusive. In a study conducted on nearly 3,000 men aged between 40-79, results showed that ED was not associated with total T levels in a linear fashion, and the association between ED and free $T$ levels was found to be weak; However, when total T levels $(<8 \mathrm{nmol} / \mathrm{L})$ the relationship between T levels and ED strengthened, and became statistically significant [2]. This suggests that ED should be regarded as a symptom of hypogonadism only when T levels are clearly subnormal.

Phosphodiesterase-5 inhibitors (PDE5-Is) promotes an erectile response through blocking the degradation of cyclic guanosine monophosphate. As a result, the corpus cavernosal smooth muscle relaxes, and this promotes a penile erection following sexual stimulation. PDE5-Is was thus shown to improve erections in up to $70 \%$ of patients with ED[3]. Therapeutic efficacy may also improve with dose escalation or when using a low-dose daily dosing strategy. However, alternating between different types of PDE5-Is did not seem to improve treatment efficacy [4, 5]. PDE5-Is have revolutionized ED treatments for patients, but nonetheless have their limitations; Although PDE5-Is has a good therapeutic effect on most ED patients, patient's existing conditions such as hypertension, dyslipidemia, poor glycemic control, and tobacco use all independently weaken the effect of PDE5-Is [6]. Interestingly, in a sample of men who failed a trial of PDE5-Is, $40 \%$ of them were still able to achieve a long-term satisfactory result after going through a $12 \mathrm{~min}$ in-office education and evaluation[4].

Similarly, in men with hypogonadism, it remains unclear whether the addition of TTh improves one's response to PDE5-Is. In Buvat et al.'s study which examined the effects of TTh on PDE5-Is non-responders, they found that the change in Erectile Function Domain Score (EFD) and rate of successful intercourse were nonsignificant within males with a normal T levels at baseline; However, when total T level of $<3 \mathrm{ng} / \mathrm{mL}$ at baseline, both EFD change and rate of successful sexual intercourse were significant [7]. Accordingly, a particular combination of TTh and tadalafil, a PDE5-I, significantly improved erectile function in ED patients with hypogonadism, even after treatment cessation [8]. At the 
meanwhile, in a Case series study, males with baseline total T levels $<4 \mathrm{ng} / \mathrm{mL}$ who unsatisfied with different PDE5-Is treated by TTh, although EFD achieve a statistically significant increase compare with baseline after TTh treatment, 65.6\% (21/32) patients were not clinically satisfied with his sexual function[9]. Furthermore, in some hypogonadism patients for whom sildenafil, another PDE5-I, treatment is effective, addition of TTh does not result in better erectile function improvement compared to placebo gel [10].

Hence, the question of whether the addition of TTh improves ED when patients with hypogonadism fail to respond to PDE5-Is is a major concern for clinicians. Thus, the present study intends to elucidate the role that TTh plays and its effect on erectile function in PDE5-Is nonresponders with hypogonadism.

\section{Materials And Methods}

This study was registered at the International prospective register of systematic reviews (PROSPERO registry number: CRD42020215241) and did not involve any human intervention. The Preferred Reporting Items for Systematic Reviews and Meta-analysis (PRISMA) statement was adhered to for the reporting of results.

Literature search

A systematic search was conducted within the databases of Pubmed, Cochrane Library, and Google Scholar in order to identify all relevant studies published up till October 2020. Terms and descriptors related to "phosphodiesterase type 5 inhibitors OR sildenafil OR tadalafil," "testosterone OR testosterone replacement," and "hypogonadal OR androgen deficiency syndrome," were combined, with the filter "human". Studies written in all languages were considered for the current study. The advanced search function was also utilized, where we limited selected article types to clinical studies and randomized controlled trials (RCTs). Trial registries (http://clinicaltrials.gov and www.who.int/trialsearch) were also searched. Lastly, to ensure we identified all relevant studies, we also conducted a manual search among the reference lists of articles that were already included at that point in time.

\section{Eligibility Criteria and Selection of Studies}

Articles were included if full texts were available, if human participants were enrolled, and if they were primary research papers. We included studies which: 1) assessed the efficacy of a combined treatment consisting of PDE5-Is and TTh in ED patients with low levels of T who were previously non-responsive to initial treatment with PDE5-Is alone 2) included control groups who were treated with PDE5-Is or TTh, with and without placebos. Exclusion criteria included the following: 1) inclusion of patients who treated with PDE5-Isreported satisfactory erections; 2) ED patients with normal T; 3 ) other therapeutic strategies employed (androgens or antiandrogens) before baseline; 4) studies with missing outcome data. Two authors (Yanhong.Liu and Xiaoyuan.Zhang) assessed all abstracts that were surfaced from the search independently and obtained the full manuscripts of papers identified via the manual search that met the selection criteria. These authors also evaluated the eligibility of the studies and extracted the required data for analysis. Any discrepancies in the selection of articles were solved by mutual agreement among the authors after discussion, and if needed, a third author was included in the discussion.

\section{Data extraction}

Two review authors (QW and WXY) independently extracted data from the selected studies, The following study characteristics were identified for each study: 1) study design and population (including the history of non-responders to treatment with different PDE5-Is); 2) T levels, 3) the form and dose of testosterone replacement used; 4) the type and dose of PDE5-Is used; 5) interventions in treatment and control groups; 6) duration of treatment; 7) outcome, specifying the percentage of patients who responded to treatment, if not already otherwise indicated in the inclusion criteria in each study. All included studies were also assessed according to the criteria for nonrandomized studies to evaluate the potential risk of bias.

We specified the primary outcome measure a priori as EFD change of the TTh plus PDE5-Is group compared to the placebo plus PDE5-IS group, and the TTh plus PDE5-Is group compared to the TTh only group. Secondary outcome measures included the number of patients with improved response to treatment with PDE5-Is, pre and post change in EFD for the various groups who underwent treatments of either TTh plus PDE5-Is, TTh or PDE5-Is alone.

Any discrepancies were resolved by discussion, and if needed, consensus was reached by involving a third author (QW).

\section{Sensitivity Analysis and Risk of Bias}

Sensitivity analyses were conducted utilizing the leave-one-out approach, and results show that there was no significant change in the direction and magnitude of the combined estimates when individual studies were excluded. Hence, this indicates that the meta-analysis has good reliability. The quality evaluation process was performed using Review Manager 5.3 (The Nordic Cochrane Centre, The Cochrane

Page $3 / 11$ 
Collaboration, Copenhagen, Denmark) as shown in Fig. 5. The included articles are all registered RCTs and fulfilled the CONSORT criteria. As there was only a small number of available trials, funnel plot asymmetry tests to evaluate publication bias could not be conducted[11].

\section{Statistical analysis}

Statistical analyses were conducted using Review Manager 5.3 (The Nordic Cochrane Centre, The Cochrane Collaboration, Copenhagen, Denmark). Associations among dichotomous outcomes were assessed using odds ratios (ORs) and their 95\% confidence interval (Cls). Associations among continuous variables were assessed using standardized mean difference (SMD) and their $95 \%$ Cls. Sensitivity analyses were also conducted by excluding trials with outliers. Next, heterogeneity between trials was quantified using the Q-test or $\mathrm{I}^{2}$. A random effect model was utilized because of the limited number of studies[11].

\section{Results}

A total of 166 studies were identified initially, and after a through selection process as shown in Fig. 1, we initial arrived at a sample of 7 RCTs to be included for analysis, all of which were published between 2004 and 2011[7, 10, 12-16]. However, after a thorough reading of the 7 RCTs, 3 articles were excluded because they did not meet the inclusion criteria. Spitzer et al[10]. only included participants who initial used 100-mg sildenafil reported satisfactory but not unresponsive erections. In trail of Aversa et al[13]. patients with T levels in hypogonadal range were not included. The remaining study conducted by Hackett et al[12]. involved type 2 Diabetes males with hypogonadism, and these patients did not receive any PDE5-Is treatment.

The rest of 4 RCTs encompassed a total of 326 patients, and the follow-up duration ranged between 10 to 13 weeks, with a mean duration of 12 weeks. Two studies [7, 14] used the PDE5-Is + placebo treatment group as their control, whereas the other 2 studies[15, 16] used the TTh as control. As the use of different control groups may influence the results of the analysis, we decided to conduct separate analyses for the 2 different types of control groups. A summary of the trials included are as shown in Table 1.

Table 1

Characteristics of the included studies

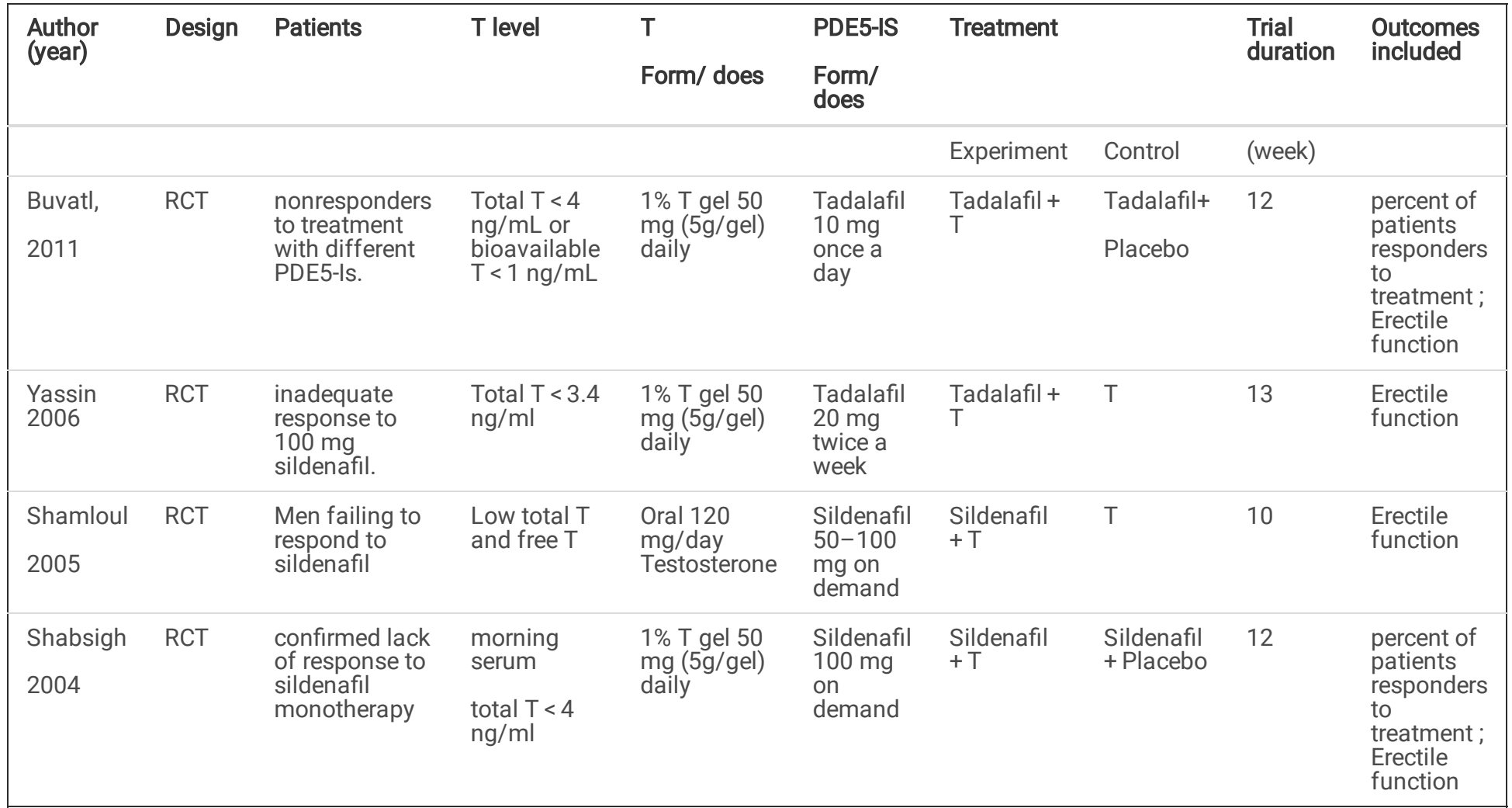

A total of 237 patients were sampled in two studies which compared the effect of TTh plus PDE5-Is group against a control consisting of placebo plus PDE5-Is group. Our results suggest that there was no significant improvement in the EFD of TTh plus PDE5-Is therapy group over the EFD of the PDE5-Is plus placebo group. The pooled SMD for EFD change was 1.20 [(-0.66-3.06), $\mathrm{I}^{2}=34 ; p=.21$; Fig. 2]. On the other hand, a total of 89 patients were sampled in rest of two studies comparing the effect of the TTh plus PDE5-Is group against the TTh only group on the 
basis of EFD; The TTh plus PDE5-Is group had a pooled SMD for EFD change was $3.16\left(95 \% \mathrm{Cl} 1.79-4.53, \mathrm{I}^{2}=63 ; p<.00001\right.$; Fig. 2$)$, and had a significantly better improvement in EFD compared to the TTh only group.

Where data pooling was possible in all 4 trials, we examined the EFD change before and after treatment of TTh plus PDE5-Is, and the SMD in improvement from baseline measured with EFD was 4.88 [(4.18-5.57), $\mathrm{I}^{2}=0 ; p<.00001$; Fig]. In the placebo and PDE5-Is groups, SMD in improvement from baseline measured with EFD was 3.15 [(1.82-4.47), $\mathrm{I}^{2}=0 ; p<.00001$; Fig. 3], and for TTh only group, it was 2.04 [(0.383.71), $\mathrm{I}^{2}=70 ; p=.02 ;$ Fig. 3].

Two of the included trials[7, 14] which compared between the treatments of TTh plus PDE5-Is group, and placebo plus PDE5-Is therapy reported on the number of patients with improved response to treatment after 8-12 weeks. 47\% of patients in the TTh plus PDE5-Is group reported an improvement, compared to only $33.0 \%$ in placebo plus PDE5-Is group, the pooled OR was $1.41\left(95 \% \mathrm{Cl} 0.79-2.54, \mathrm{I}^{2}=0 ; \mathrm{P}=0.25\right.$; Fig. 4). For sensitivity analysis, we then excluded each study to analyze the change in the pooled effect, which was not statistically significant.

\section{Discussion}

TTh treatment remains a controversial topic, even after more than 70 years of clinical use, with a significant portion of the research literature providing evidence that TTh does improve sexual symptoms in men with ED. This may be due in part to various testosterone preparations possibly having differing modes of action [17-20]. Previous study have indicated that TTh treatment was ineffective in improving ED when there were high serum levels of estradiol [21]. Clinically, on-demand administration tadalafil was able to reduce serum estradiol levels significantly, but the testosterone/estradiol ratio also rose significantly regardless of whether total or free $T$ rises [22]. Thus, some researchers recommend that clinicians consider starting PDE5-Is therapy during the first consultation for ED, without waiting for confirmation of a normal serum T leve[23]. At the same time, a qualitative systematic review concluded that TTh did not show consistent benefits for sexual function [24]. Another systematic review which included 17 RCTs, comprising of a total of 3165 men with hypogonadism indicated that erectile function did not differ significantly between individuals who received the TTh or those who received placebos[25].

Previous meta-analyses also reported that a positive effect of PDE5-Is was further improved with the co-administration of testosterone only in uncontrolled studies, but not in placebo-controlled studies[26]. Our analysis suggests that dual treatment with TTh and PDE5-Is significantly improves EFD when compared to the control group of TTh only. In patients who received dual treatment(TTh and PDE5-Is), there was a higher increase in EFD (4.88 point), but for TTh treatment only it was 2.04 point only. This supports the theory that TTh may facilitate the pharmacological effects of PDE5-Is[27]. The PDE5 gene is expressed less as males age, as well as in men with hypogonadism. Hence, TTh treatment may possibly be able to restore the expression of the PDE5 gene, through regulating its gene expression directly[28]. Accordingly, there was an observed mean increase of 2.3 point in EFD scores for patients with mild ED who were treated with TTh, but not for those with more severe ED. In our meta-analysis, only 2 of the selected articles considered the seriousness of ED. In Shabsigh et al.'s study, $69 \%$ of placebo gel control group had mild to moderate ED, while $81 \%$ in dual treatment group had mild to moderate ED.[14]. In Yassin et al.'s study, $74.3 \%$ of the TTh group had mild to moderate ED compared to $67.7 \%$ in the dual treatment group [16]. Hence, for men with milder ED, TTh alone may be a possible treatment option[29].

There was also a higher percentage of patients with improved response to treatment after 8-12 weeks for the group receiving treatment of TTh plus PDE5-Is, at $41.7 \%$, compared to $33.0 \%$ for the group receiving the placebo plus PDE5-Is. In patients who received dual treatment(TTh and PDE5-Is), there was a higher increase in EFD (4.88 point) when compared with patients who underwent only PDE5-Is treatment (3.15 point), although when PDE5-Is treatment was used as the control group, the change of EFD did not reach statistical difference. This can be attributed to a number of factors. Firstly, ED patients treatment with PDE5-Is increased total T levels by 1.15-1.73 ng/mI[30, 31], significant erectile function improvements were seen only in samples with a lower testosterone threshold, and further increases in testosterone levels do not confer further benefits on erectile function if testosterone threshold has already been hit [32]. So it is unclear whether the additive benefit of TTh was negated by the potentially direct effect of PDE5-Is on serum T levels. Secondly, a meta-analysis of 14 RCTs found that when the testosterone threshold was less than $2.3 \mathrm{nmol} / \mathrm{I}$, EFD increased by 2.95 after TTh, compared to only a 1.47 point increase in EFD when the total T threshold was less than $3.5 \mathrm{nmol} / \mathrm{I}$ [33]. Three selected articles described the classification of the total T levels at baseline. In Yassin et al.'s study, total T levels of $<2 \mathrm{ng} / \mathrm{mL}$ were observed in $20.6 \%$ of the TTh group, and in $17.6 \%$ of the dual treatment group [16], while in Shabsigh et al.'s study, total T levels of $<2 \mathrm{ng} / \mathrm{mL}$ were observed in $33 \%$ of the placebo gel group, compared to only $5 \%$ of the dual treatment group [14]. In addition, in Buvat et al.'s study, $28.1 \%$ of the sample were bounded by a total T of $<1.45 \mathrm{ng} / \mathrm{ml}$ [7]. Most of the included patients with a mild degree of androgen deficiency might possibly weakening the therapeutic effect of TTh, as TTh was more effective in patients with moderate to severe androgen deficiency. It must be noted that imbalances in total T distribution, as well as in ED grading can result in biases in the analyses. Moreover, as a lack of sexual activity also could have caused subclinical hypogonadism, TTh may benefit in ED patients restoring sexual activity and further increase their testosterone levels at a normal range[34]. 
Only two types of PDE5-Is (sildenafil, tadalafil) were used in the selected studies, and this may potentially result in a bias, even though previous meta-analyses indicate that there are no significant difference in the efficacy of PDE5-Is relative to each other[3]. A 10-20 mg dosage of tadalafil was associated with greater improvement in the mean proportion of successful sexual intercourse attempts (76.9\%) compared to a dosage of $100 \mathrm{mg}$ sildenafil $(72.2 \%)$. On the other hand, the mean change in EFD did not differ between groups[35, 36]. There was no significant dose-response effect when tadalafil was used [37]. The dose of sildenafil used varied among the included studies, where one particular study used 50-100 mg on demand [15] and the other used a dosage of $100 \mathrm{mg}$ on demand [14]. There was only significant improvement in sexual intercourse success and erectile function in using a sildenafil dosage of $50 \mathrm{mg}$ when it was compared to a $25 \mathrm{mg}$ dose, but there was no difference in the improvements for both 100mf and 50mg doses[38].

In contrast with certain reviews that were published previously, we only included RCTs that enrolled initial PDE5-Is non-responders with hypogonadism. Our study also had several limitations. First, only 2 of the included articles described the classification of baseline T levels and the severity of ED, and the distribution of such participants across the various groups studied was also uneven. Second, the included studies used various cut-off values for the testosterone to determine hypogonadism. Third, the duration of treatment with TTh varied among the included studies and this difference in duration may have affected the outcomes. Therefore, further high-quality research studies need to be conducted to better elucidate the effects of the TTh treatment on patients with hypogonadism who are unresponsive to phosphodiesterase-5 inhibitors alone.

\section{Conclusion}

The present meta-analysis and systematic review conducted suggests that the effect of combined TTh and PDE5-Is therapy in males with ED and hypogonadism who are initial unresponsive to PDE5-Is resulted in a significant improvement in erectile function when compared with PDE5-Is and TTh therapy only. Moreover, dual treatment(TTh and PDE5-Is) also associated with greater improvement in proportion of successful sexual intercourse attempts (41.7\%) compared to PDE5-Is monotherapy (33.0\%). TTh monotherapy conducted for a short period of time in cases of hypogonadism does not seem to more helpful in men who did not respond to initial treatment with PDE5-Is alone. The fact that TTh treatment seems to be more beneficial for men with severe hypogonadism suggests that further research are still needed to clarify whether such a combination therapy may be useful in difficult-to-treat ED patients who do not respond to PDE5-Is.

\section{Abbreviations}

PDE5-Is: phosphodiesterase-5 inhibitors; TTh: testosterone therapy; ED erectile dysfunction; T: testosterone; RCTs: randomized controlled trials; ORs: odds ratios; Cls: confidence interval; SMD: standardized mean difference

\section{Declarations}

- $\quad$ Ethics approval and consent to participate

Not applicable

- $\quad$ Consent to publish

Not applicable

- $\quad$ Availability of data and materials

All data generated or analysed during this study are included in this published article [and its supplementary information files].

\section{- $\quad$ Competing interests}

All authors have read and approved the manuscript. The authors declare that they have no competing interests.

\section{- $\quad$ Funding}

Study on the effect of oxLDL on progesterone production by HIF pathway on infertility in obese women-Jilin Provincial Finance Department This funder support the scientific English editing and the Article-Processing Charge (APC) payment.

\section{- $\quad$ Authors' Contributions}


QW designed and guided the study; YH L participated in literature search and review, meta-analysis, and interpretation of results; XW Y performed the meta-analysis and helped draft the manuscript.; XY Z analyzed included and excluded studies, helped summarize the collected evidence. All authors read and approved the final manuscript.

Acknowledgements

Not applicable

\section{References}

1. Araujo AB, Esche GR, Kupelian V, O’Donnell AB, Travison TG, Williams RE, Clark RV, McKinlay JB. Prevalence of symptomatic androgen deficiency in men. The Journal of Clinical Endocrinology Metabolism. 2007;92(11):4241-7.

2. O'Connor DB, Lee DM, Corona G, Forti G, Tajar A, O'Neill TW, Pendleton N, Bartfai G, Boonen S, Casanueva FF. The relationships between sex hormones and sexual function in middle-aged and older European men. The Journal of Clinical Endocrinology Metabolism. 2011;96(10):E1577-87.

3. Chen L, Staubli SE, Schneider MP, Kessels AG, Ivic S, Bachmann LM, Kessler TM. Phosphodiesterase 5 inhibitors for the treatment of erectile dysfunction: a trade-off network meta-analysis. European urology. 2015;68(4):674-80.

4. Mulhall JP, Giraldi A, Hackett G, Hellstrom WJ, Jannini EA, Rubio-Aurioles E, Trost L, Hassan TA. The 2018 revision to the process of care model for management of erectile dysfunction. J Sex Med. 2018;15(10):1434-45.

5. Atiemo HO, Szostak MJ, Sklar GN. Salvage of sildenafil failures referred from primary care physicians. The Journal of urology. 2003;170(6):2356-8.

6. Sadovsky R, Brock GB, Gray M, Jensen PK, Gutkin SW, Sorsaburu S. Optimizing treatment outcomes with phosphodiesterase type 5 inhibitors for erectile dysfunction: Opening windows to enhanced sexual function and overall health. J Am Acad Nurse Pract. 2011;23(6):320-30.

7. Buvat J, Montorsi F, Maggi M, Porst H, Kaipia A, Colson MH, Cuzin B, Moncada I, Martin-Morales A, Yassin A. Hypogonadal men nonresponders to the PDE5 inhibitor tadalafil benefit from normalization of testosterone levels with a $1 \%$ hydroalcoholic testosterone gel in the treatment of erectile dysfunction (TADTEST study). J Sex Med. 2011;8(1):284-93.

8. Park MG, Yeo JK, Cho DY, Kim JW, Kim JW, Oh MM, Kim JJ. Moon du G: The efficacy of combination treatment with injectable testosterone undecanoate and daily tadalafil for erectile dysfunction with testosterone deficiency syndrome. J Sex Med. 2015;12(4):96674.

9. Hwang TI, Chen HE, Tsai TF, Lin YC. Combined use of androgen and sildenafil for hypogonadal patients unresponsive to sildenafil alone. Int J Impot Res. 2006;18(4):400-4.

10. Spitzer M, Basaria S, Travison TG, Davda MN, Paley A, Cohen B, Mazer NA, Knapp PE, Hanka S, Lakshman KM, et al. Effect of testosterone replacement on response to sildenafil citrate in men with erectile dysfunction: a parallel, randomized trial. Ann Intern Med. 2012;157(10):681-91.

11. Chen B, Benedetti A. Quantifying heterogeneity in individual participant data meta-analysis with binary outcomes. Systematic reviews. 2017;6(1):243.

12. Hackett G, Cole N, Bhartia M, Kennedy D, Raju J, Wilkinson P. Testosterone Replacement Therapy with Long-Acting Testosterone Undecanoate Improves Sexual Function and Quality-of-Life Parameters vs. Placebo in a Population of Men with Type 2 Diabetes. J Sex Med. 2013;10(6):1612-27.

13. Aversa A, Isidori AM, Spera G, Lenzi A, Fabbri A. Androgens improve cavernous vasodilation and response to sildenafil in patients with erectile dysfunction. Clin Endocrinol. 2003;58(5):632-8.

14. Shabsigh R, Kaufman JM, Steidle C, Padma-Nathan H. Randomized study of testosterone gel as adjunctive therapy to sildenafil in hypogonadal men with erectile dysfunction who do not respond to sildenafil alone. J Urol. 2004;172(2):658-63.

15. Shamloul R, Ghanem H, Fahmy I, El-Meleigy A, Ashoor S, Elnashaar A, Kamel I. Testosterone therapy can enhance erectile function response to sildenafil in patients with PADAM: a pilot study. The Journal of Sexual Medicine. 2005;2(4):559-64.

16. Yassin A, Saad F, Diede H. Testosterone and erectile function in hypogonadal men unresponsive to tadalafil: results from an open-label uncontrolled study. Andrologia. 2006;38(2):61-8.

17. Zhu J, Zhang W, Ou N, Song Y, Kang J, Liang Z, Hu R, Yang Y, Liu X. Do testosterone supplements enhance response to phosphodiesterase 5 inhibitors in men with erectile dysfunction and hypogonadism: a systematic review and meta-analysis. Translational Andrology Urology. 2020;9(2):591. 
18. Corona G, Maseroli E, Maggi M. Injectable testosterone undecanoate for the treatment of hypogonadism. Expert opinion on pharmacotherapy. 2014;15(13):1903-26.

19. Jain P, Rademaker AW, Mcvary KT. Testosterone supplementation for erectile dysfunction: results of a meta-analysis. The Journal of urology. 2000;164(2):371-5.

20. Gur S, Alzweri L, Yilmaz-Oral D, Kaya-Sezginer E, Abdel-Mageed AB, Dick B, Sikka SC, Volkan Oztekin C, Hellstrom WJ: Testosterone positively regulates functional responses and nitric oxide expression in the isolated human corpus cavernosum. Andrology 2020.

21. Kataoka T, Hotta Y, Ohno M, Maeda Y, Kimura K. Limited effect of testosterone treatment for erectile dysfunction caused by high-estrogen levels in rats. Int J Impot Res. 2013;25(6):201-5.

22. Niikura S, Yokoyama O, Komatsu K, Yotsuyanagi S, Mizuno T, Namiki M. A causative factor of copulatory disorder in rats following social stress. The Journal of urology. 2002;168(2):843-9.

23. Mulhall JP, Brock GB, Glina S, Baygani S, Donatucci CF, Maggi M. Impact of Baseline Total Testosterone Level on Successful Treatment of Sexual Dysfunction in Men Taking Once-Daily Tadalafil 5 mg for Lower Urinary Tract Symptoms and Benign Prostatic Hyperplasia: An Integrated Analysis of Three Randomized Controlled Trials. J Sex Med. 2016;13(5):843-51.

24. Huo S, Scialli AR, McGarvey S, Hill E, Tügertimur B, Hogenmiller A, Hirsch Al, Fugh-Berman A. Treatment of men for "low testosterone”: a systematic review. PloS one. 2016;11(9):e0162480.

25. Elliott J, Kelly SE, Millar AC, Peterson J, Chen L, Johnston A, Kotb A, Skidmore B, Bai Z, Mamdani M, et al. Testosterone therapy in hypogonadal men: a systematic review and network meta-analysis. BMJ open. 2017;7(11):e015284.

26. Corona G, Isidori AM, Buvat J, Aversa A, Rastrelli G, Hackett G, Rochira V, Sforza A, Lenzi A, Mannucci E. Testosterone supplementation and sexual function: a meta-analysis study. J Sex Med. 2014;11(6):1577-92.

27. Aversa A, Duca Y, Condorelli RA, Calogero AE, La Vignera S. Androgen deficiency and phosphodiesterase type 5 expression changes in aging male: therapeutic implications. Frontiers in Endocrinology. 2019;10:225.

28. Lee DS, Sohn DW. The Role of Testosterone in Amplifying the Effect of a Phosphodiesterase Type 5 Inhibitor After Pelvic Irradiation. The Journal of Sexual Medicine 2020.

29. Rosen RC, Allen KR, Ni X, Araujo AB. Minimal clinically important differences in the erectile function domain of the International Index of Erectile Function scale. European urology. 2011;60(5):1010-6.

30. Carosa E, Martini P, Brandetti F, Di Stasi SM, Lombardo F, Lenzi A, Jannini EA. Type V phosphodiesterase inhibitor treatments for erectile dysfunction increase testosterone levels. Clin Endocrinol. 2004;61(3):382-6.

31. Spitzer M, Basaria S, Travison TG, Davda MN, DeRogatis L, Bhasin S. The effect of testosterone on mood and well-being in men with erectile dysfunction in a randomized, placebo-controlled trial. Andrology. 2013;1(3):475-82.

32. Buena F, Swerdloff RS, Steiner BS, Lutchmansingh P, Peterson MA, Pandian MR, Galmarini M, Bhasin S. Sexual function does not change when serum testosterone levels are pharmacologically varied within the normal male range. Fertility sterility. 1993;59(5):1118-23.

33. Corona G, Rastrelli G, Morgentaler A, Sforza A, Mannucci E, Maggi M. Meta-analysis of results of testosterone therapy on sexual function based on international index of erectile function scores. European urology. 2017;72(6):1000-11.

34. Maggi M, Filippi S, Vignozzi L, Rastrelli G: Controversial aspects of testosterone in the regulation of sexual function in late-onset hypogonadism. Andrology 2020.

35. Eardley I, Mirone V, Montorsi F, Ralph D, Kell P, Warner MR, Zhao Y, Beardsworth A. An open-label, multicentre, randomized, crossover study comparing sildenafil citrate and tadalafil for treating erectile dysfunction in men naive to phosphodiesterase 5 inhibitor therapy. BJU Int. 2005;96(9):1323-32.

36. Tolrà JR, Campaña JMC, Ciutat LF, Miranda EF. Prospective, randomized, open-label, fixed-dose, crossover study to establish preference of patients with erectile dysfunction after taking the three PDE-5 inhibitors. The Journal of Sexual Medicine. 2006;3(5):901-9.

37. Hatzichristou D, Gambla M, Rubio-Aurioles E, Buvat J, Brock G, Spera G, Rose L, Lording D, Liang S. Efficacy of tadalafil once daily in men with diabetes mellitus and erectile dysfunction. Diabetic medicine. 2008;25(2):138-46.

38. Goldstein I, Lue TF, Padma-Nathan H, Rosen RC, Steers WD, Wicker PA. Oral sildenafil in the treatment of erectile dysfunction. N Engl J Med. 1998;338(20):1397-404.

\section{Tables}

Table 1 Characteristics of the included studies 


\begin{tabular}{|c|c|c|c|c|c|c|c|c|c|}
\hline \multirow{3}{*}{$\begin{array}{l}\text { Author } \\
\text { (year) }\end{array}$} & \multirow[t]{3}{*}{ Design } & \multirow[t]{3}{*}{ Patients } & \multirow[t]{3}{*}{ T level } & \multirow{3}{*}{$\begin{array}{l}\text { T } \\
\text { Form/ does }\end{array}$} & \multirow{3}{*}{$\begin{array}{l}\text { PDE5-IS } \\
\text { Form/ } \\
\text { does }\end{array}$} & \multirow{2}{*}{\multicolumn{2}{|c|}{ Treatment }} & \multirow{2}{*}{$\begin{array}{l}\text { Trial } \\
\text { duration }\end{array}$} & \multirow{3}{*}{$\begin{array}{l}\text { Outcomes } \\
\text { included }\end{array}$} \\
\hline & & & & & & & & & \\
\hline & & & & & & Experiment & Control & (week) & \\
\hline $\begin{array}{l}\text { Buvatl, } \\
2011\end{array}$ & RCT & $\begin{array}{l}\text { nonresponders } \\
\text { to treatment } \\
\text { with different } \\
\text { PDE5-Is. }\end{array}$ & $\begin{array}{l}\text { Total } \mathrm{T}<4 \\
\text { ng/mL or } \\
\text { bioavailable } \\
\mathrm{T}<1 \mathrm{ng} / \mathrm{mL}\end{array}$ & $\begin{array}{l}1 \% \text { T gel } 50 \\
\text { mg }(5 \mathrm{~g} / \mathrm{gel}) \\
\text { daily }\end{array}$ & $\begin{array}{l}\text { Tadalafil } \\
10 \mathrm{mg} \\
\text { once a } \\
\text { day }\end{array}$ & Tadalafil+T & $\begin{array}{l}\text { Tadalafil+ } \\
\text { Placebo }\end{array}$ & 12 & $\begin{array}{l}\text { percent of } \\
\text { patients } \\
\text { responders } \\
\text { to } \\
\text { treatment ; } \\
\text { Erectile } \\
\text { function }\end{array}$ \\
\hline $\begin{array}{l}\text { Yassin } \\
2006\end{array}$ & RCT & $\begin{array}{l}\text { inadequate } \\
\text { response to } \\
100 \mathrm{mg} \\
\text { sildenafil. }\end{array}$ & $\begin{array}{l}\text { Total T <3.4 } \\
\mathrm{ng} / \mathrm{ml}\end{array}$ & $\begin{array}{l}1 \% \mathrm{~T} \text { gel } 50 \\
\text { mg }(5 \mathrm{~g} / \mathrm{gel}) \\
\text { daily }\end{array}$ & $\begin{array}{l}\text { Tadalafil } \\
20 \mathrm{mg} \\
\text { twice a } \\
\text { week }\end{array}$ & Tadalafil+T & $\mathrm{T}$ & 13 & $\begin{array}{l}\text { Erectile } \\
\text { function }\end{array}$ \\
\hline $\begin{array}{l}\text { Shamloul } \\
2005\end{array}$ & RCT & $\begin{array}{l}\text { Men failing to } \\
\text { respond to } \\
\text { sildenafil }\end{array}$ & $\begin{array}{l}\text { Low total } \mathrm{T} \\
\text { and free } \mathrm{T}\end{array}$ & $\begin{array}{l}\text { Oral } 120 \\
\text { mg/day } \\
\text { Testosterone }\end{array}$ & $\begin{array}{l}\text { Sildenafil } \\
50-100 \\
\text { mg on } \\
\text { demand }\end{array}$ & Sildenafil+T & $\mathrm{T}$ & 10 & $\begin{array}{l}\text { Erectile } \\
\text { function }\end{array}$ \\
\hline $\begin{array}{l}\text { Shabsigh } \\
2004\end{array}$ & RCT & $\begin{array}{l}\text { confirmed lack } \\
\text { of response to } \\
\text { sildenafil } \\
\text { monotherapy }\end{array}$ & $\begin{array}{l}\text { morning } \\
\text { serum } \\
\text { total } \mathrm{T}<4 \\
\mathrm{ng} / \mathrm{ml}\end{array}$ & $\begin{array}{l}1 \% \text { T gel } 50 \\
\text { mg (5g/gel) } \\
\text { daily }\end{array}$ & $\begin{array}{l}\text { Sildenafil } \\
100 \mathrm{mg} \\
\text { on } \\
\text { demand }\end{array}$ & Sildenafil+T & $\begin{array}{l}\text { Sildenafil } \\
\text { +Placebo }\end{array}$ & 12 & $\begin{array}{l}\text { percent of } \\
\text { patients } \\
\text { responders } \\
\text { to } \\
\text { treatment ; } \\
\text { Erectile } \\
\text { function }\end{array}$ \\
\hline
\end{tabular}

\section{Figures}

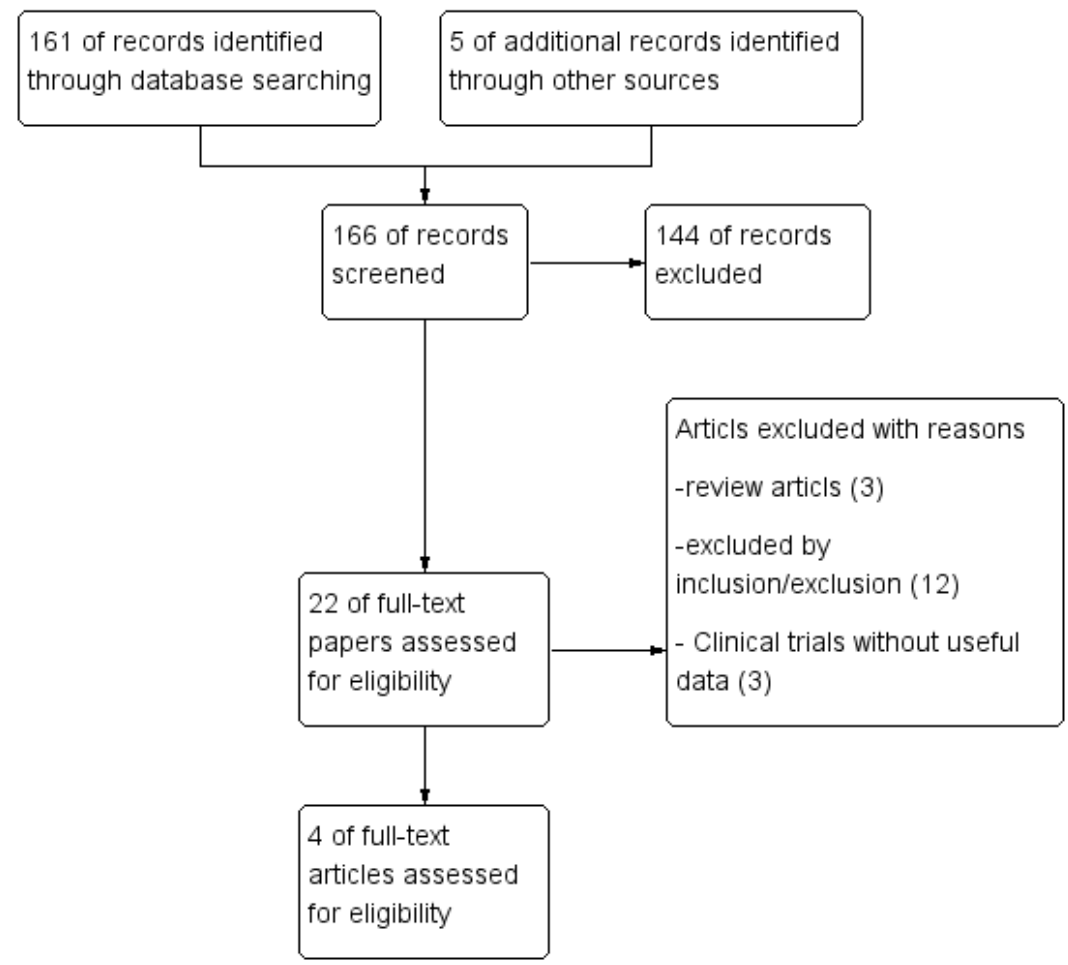

\section{Figure 1}

Flow chart for the trial identification and selection process. 


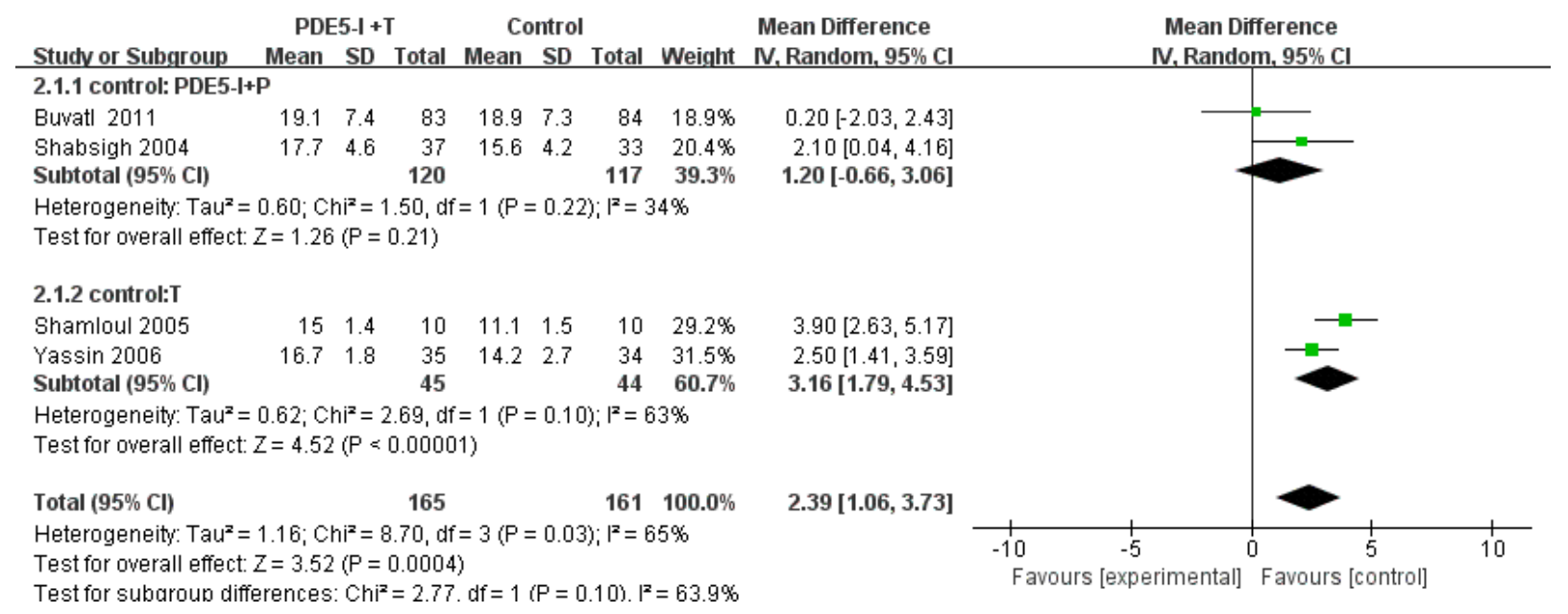

Figure 2

Subgroup meta-analysis based on control treatment in the selected studies

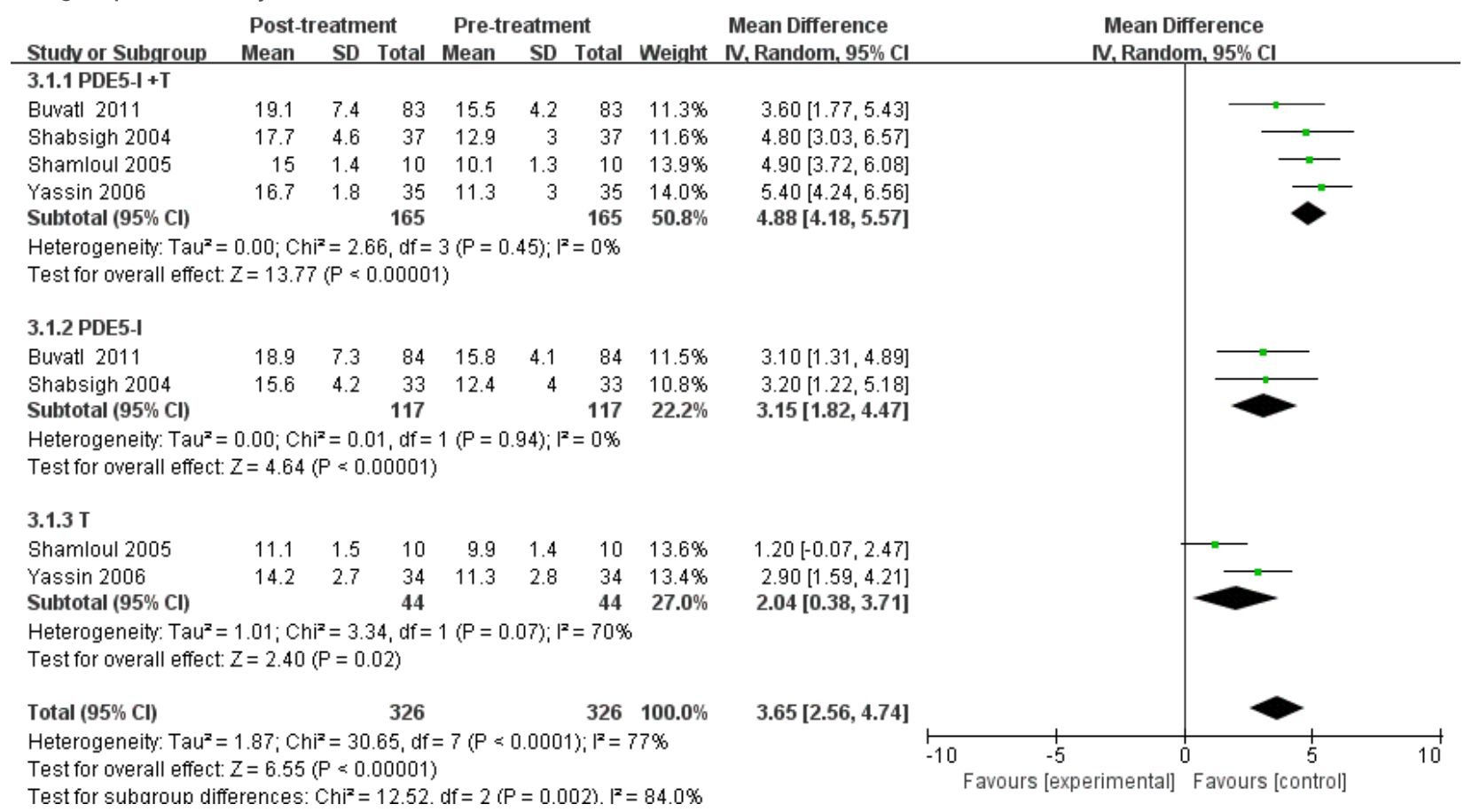

\section{Figure 3}

Subgroup meta-analysis the change of post-treatment and pretreatment in the selected studies.

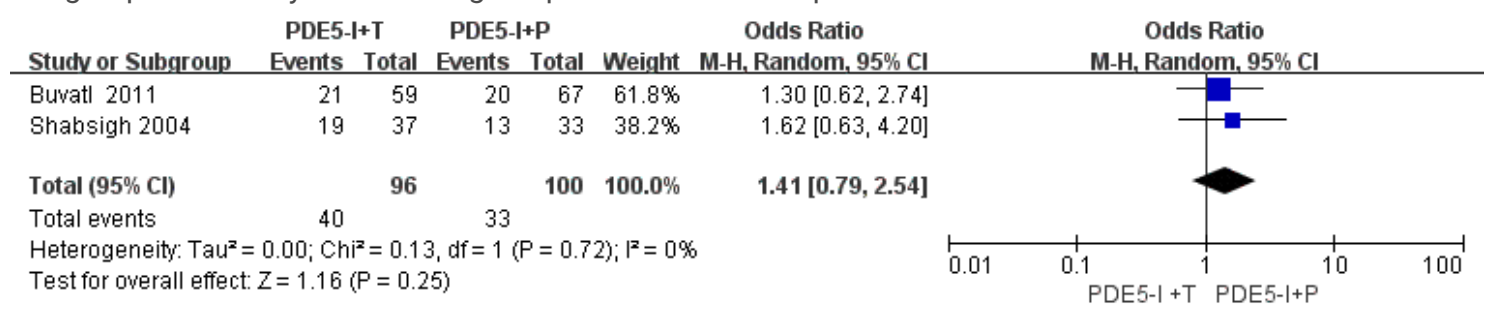

Figure 4

Forest plot demonstrating relative risk for patients responders to treatment rates when using PDE5-I+T or PDE5-I+P.

\section{Supplementary Files}


This is a list of supplementary files associated with this preprint. Click to download.

- fig5.png

- PRISMA2009checklist.doc 